\title{
Green synthesis of silver nanoparticles with antimicrobial and azo dye (Congo red) degradation properties using Amaranthus gangeticus Linn leaf extract
}

\author{
Haradhan Kolya ${ }^{1}$, Parthapratim Maiti ${ }^{2}$, Akhil Pandey ${ }^{3}$ and Tridib Tripathy ${ }^{1 *}$ (1)
}

\begin{abstract}
Background: The present paper describes a less time-consuming and eco-friendly method for the synthesis of silver nanoparticles (AgNPs) using an aqueous solution of silver nitrate and Amaranthus gangeticus Linn (Chinese spinach) leaf extract. The synthesized AgNPs which are to be used as an antimicrobial and Congo red dye is to be used as a toxic-degrading agent.

Methods: AgNP was prepared by the reduction of silver nitrate solution by the leaf extract of Amarranthus Gangeticus Linn leaf extract in aqueous medium on heating for about 15 mins at $80{ }^{\circ} \mathrm{C}$ in presence of one drop 0.05 (M) NaOH.

Results: The size of the synthesized silver nanoparticles (AgNPs) using Amaranthus gangeticus Linn leaf extract and aqueous solution of silver nitrate $\left(10^{-3} \mathrm{M}\right)$ are formed at their stable condition within the range of 11-15 $\mathrm{nm}$. AgNPs are obtained by this process within a couple of minutes of reaction without using reducing and stabilizing agents or harsh conditions. High-resolution transmission electron microscope (HR-TEM), selected area electron diffraction (SAED), ultraviolet-visible (UV-VIS) spectroscopy, and Fourier transform infrared spectroscopy (FTIR) are used to characterize the prepared AgNPs which show that the nanoparticles are globular in shape and polycrystalline. The synthesized silver nanoparticles showed inhibitory activity towards Gram positive, Gram negative bacteria and fungus and also showed good Congo red dye-degrading agents.
\end{abstract}

Conclusions: The overall outcome of this study suggests that green synthesis AgNPs hold promise as a potent antibacterial and antifungal agent. The particles obtained were also found to degrade toxic Congo red dye.

Keywords: Silver nanoparticles, Antibacterial activity, Chinese red spinach, Congo red

\section{Background}

Over the past few years, synthesis of metal nanoparticles is one of the upcoming areas of research in the field of material science owing to their wide variety of applications in the field of catalysis (Kalidindi and Jadirdar 2012), photonics (Shen et al. 2000), chemical and bio-sensing (Zayats et al. 2003), medicine (Jotterand and Alexander 2011; Etheridge et al. 2013) etc. Nano crystalline silver is well known for possessing an inhibitory effect towards many

\footnotetext{
*Correspondence: tridib_tripathy@yahoo.co.in

${ }^{1}$ Postgraduate Division of Chemistry, Midnapore College (Autonomous), Midnapore, Paschim Medinipur 721101, West Bengal, India

Full list of author information is available at the end of the article
}

bacterial stains and microorganisms (Zhang et al. 2012; Prabhu and Poulose 2012). Silver nanoparticles were synthesized using various chemical and biological approaches (Ericka et al. 2013; Shankar et al. 2003; Bar et al. 2009; Sivaram et al. 2009; Ahmad et al. 2010; and Dubey et al. 2010). Even though silver nanoparticles are considered bio-compatible, chemical synthesis methods may lead to the presence of some toxic chemicals absorbed on the metallic surface that may have adverse effects in medical applications (Bhattcharya and Mukherjee 2008). Therefore, there is an increasing demand of green procedure for synthesizing metal nanoparticles which are free from the use of toxic chemicals. 
Many green methods and biological approaches for silver nanoparticles' synthesis using extracts of different plants (Nalvothula et al. 2014; Jha and Prasad 2010; Mandal et al. 2006 and Sharma et al. 2009) microorganisms, including bacteria (Lengke et al. 2007) and fungi (El-Rafie et al. 2010), are reported till date. In the present investigation, we have prepared AgNPs using the leaf extract of Chinese red spinach (Amaranthus gangeticus Linn) (shown in Fig. 1). It is a natural shrub which is found abundantly in our environment and mainly used as food materials. The leaves of these shrubs contain various amino acids such as arginine, histidine, leucine, isoleucine, lysine, methionine, phenyl alanine, tyrosine etc. (Reyad-ul-Ferdous et al. 2015, Srinivas et al. 2011). The antibacterial activity of the prepared AgNPs was studied into the Gram positive and Gram negative bacteria namely Bacillus subtilis and Shigelle flexineri, respectively, and its antifungal activity was studied on the Sclerotinia sp. fungi. For the catalytic activity of AgNPs for the degradation of a toxic azo dye, Congo red was evaluated. The prepared AgNPs by the present method showed excellent antibacterial/fungal activity against both the bacterial/fungal stains used and showed a good catalytic activity for the degradation of the Congo red dye.

\section{Methods}

\section{Materials}

Congo red, methyl alcohol, and potassium bromide were procured from Loba chemie, Mumbai, India. Bacillus

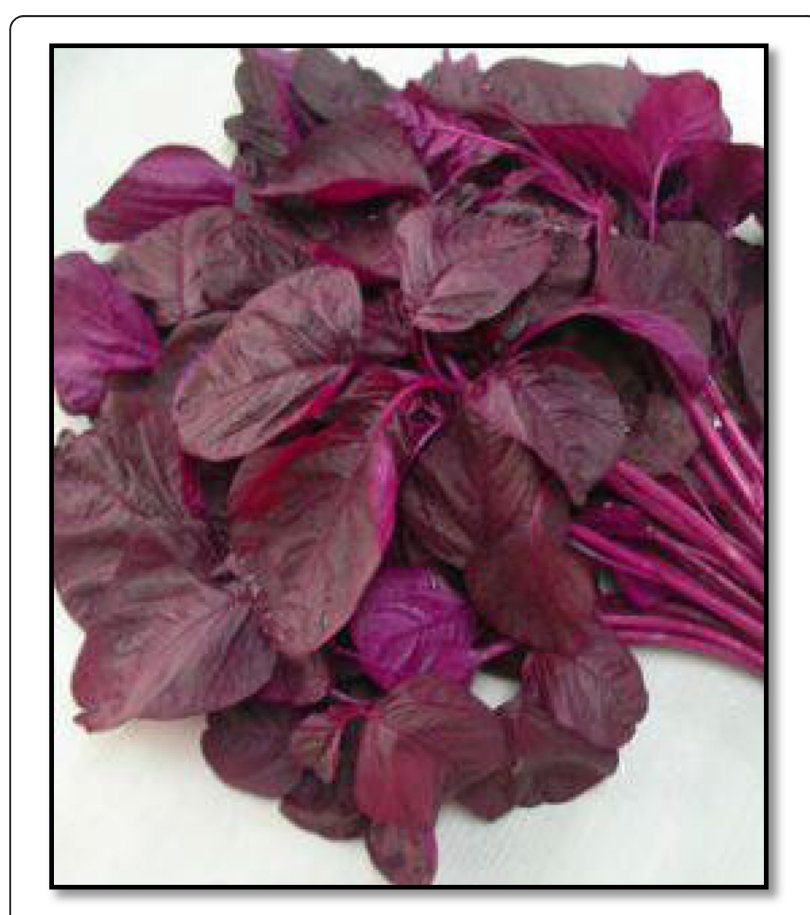

Fig. 1 Chinese red spinach (Amaranthus gangeticus Linn) plant subtilis-11774, Shigella flexneri-2022 were collected from American Type Culture Collection (ATCC), USA. Fungus, collected from Amaranthus gangeticus Linn plants (Chinese red spinach), were procured from the local market of Midnapore town, Paschim Medinipur, West Bengal, India. All the solutions were prepared by double-distilled water.

\section{Experimental}

\section{Preparation of leaf extract}

The freshly collected leaves of Amaranthus gangeticus Linn plant were cleaned several times using distilled water. The washed leaves were chopped into small sizes. Thereafter, the small-sized leaves were compactly packed into a thimble and then the solvent extraction (methanol, water $=1: 3$ ) was performed using a Soxhlet apparatus. Such solvent extraction leads to remove desirable compounds from the leaves and make them soluble in the used solvent having a definite polarity.

\section{Preparation of silver nanoparticles}

The $5 \mathrm{ml}$ of prepared $10^{-3} \mathrm{M} \mathrm{AgNO}_{3}$ solution was taken in a freshly washed $50-\mathrm{ml}$ beaker and then it was heated for about $5 \mathrm{~min}$ at $80{ }^{\circ} \mathrm{C}$. Thereafter, $1.5 \mathrm{ml}$ of plant leaf extract was added followed by one drop of $0.05 \mathrm{M}$ $\mathrm{NaOH}$. The solution was further heated up to $20 \mathrm{~min}$ in $80{ }^{\circ} \mathrm{C}$ at which the colour of the solution changed to a brownish yellow colour which had indicated the formation of silver nanoparticles (AgNPs) (Nalvothula et al. 2014). The concentration of $\mathrm{AgNO}_{3}$ solution and leaf extract was also varied at 4 to $6 \mathrm{mM}$ of $\mathrm{AgNO}_{3}$ and 1 to $2 \mathrm{ml}$, respectively, keeping other parameters constant. Ultraviolet-visible (UV-VIS) spectra showed a strong absorption peak (SPR) band at $416 \mathrm{~nm}$ thus indicating the formation of silver nanoparticles. The synthesized AgNPs (hydrosol) were centrifuged at 12,000 rpm for 20 min. Thereafter, the AgNPs were redispersed in sterile distilled water for further use.

\section{Study of antibacterial activity}

The antibacterial activity of synthesized AgNPs was investigated by standard agar-well diffusion method (Bauer et al. 1966; Awhad et al. 2013) into one Gram positive (Bacillus subtilis) and one Gram negative (Shigella flexneri) bacteria. Solidified nutrient agar was cast onto petriplates, and the plates containing nutrient medium were evenly inoculated with $100 \mu \mathrm{g}(108 \mathrm{CFU} / \mathrm{ml})$ separately. The wells are prepared on the agar plate with the help of cork borer $(0.6 \mathrm{~cm}$ diameter). Levofloxacin, $5 \mu \mathrm{g} /$ disc, which was used as a standard, was placed in the well of each plate. The synthesized and redispersed hydrosol $(30 \mathrm{mg} /$ $\mathrm{ml}$ ) was loaded onto the wells of each plate. The plates were then incubated $24 \mathrm{~h}$ at $37{ }^{\circ} \mathrm{C}$, and the antibacterial 
activity was determined by measuring the diameter of the inhibition zone and expressed in millimeter.

\section{Study of antifungal activity}

Actively growing fungal plant Sclerotinia sp. pathogens were aseptically transformed on to midpoint of sterile standard potato dextrose agar (PDA) plates and incubated at $25{ }^{\circ} \mathrm{C}$ for 2 days. After 2 days, three wells $(5 \mathrm{~mm})$ were prepared by using a sterile cork borer at equal distance around the mycelia growth of pathogenic fungi. The prepared AgNPs at different concentrations ([1] $0.4 \mu \mathrm{g} / \mathrm{ml}$, [2] $0.2 \mu \mathrm{g} / \mathrm{ml}$, [3] $0.1 \mu \mathrm{g} / \mathrm{ml}$ ) were loaded onto each well separately and allowed to grow for 3 days. The inhibition of growth of plant pathogenic fungi around the well refers to antifungal activity of the antimicrobial sample (here AgNPs). Antifungal activity test was done against one plant pathogenic fungi Sclerotinia sp.

\section{Congo red dye degradation}

Aqueous solution of Congo red $\left(10^{-3} \mathrm{M}\right)$ and $0.5 \mathrm{M}$ ethanolic solution of sodium borohydride were prepared. Thereafter, a solution was prepared by adding $5 \mathrm{ml} 10^{-3} \mathrm{M}$ Congo red solution with $1 \mathrm{ml}$ of ethanolic borohydride solution. From this solution, $1.5 \mathrm{ml}$ was taken in an ultraviolet (UV) quartz cuvette. UVVIS absorption study was done to record the change in absorbance at a time interval $1.5 \mathrm{~min}$ until the solution became completely colourless.

\section{Characterization of AgNPs}

UV-VIS adsorption spectra were measured in a $1-\mathrm{cm}$ quartz cuvette using Shimadzu-1800 (Japan) spectrophotometer. Morphology and size of AgNPs were investigated using JEOL-JEM-2100 high-resolution transmission electron microscope (HR-TEM). Sample of HR-TEM study was prepared by placing a drop of redispersed silver sol onto a carbon film, supported on a copper grid followed by solvent evaporation. FTIR spectrum of the AgNPs was taken in a Perkin Elmer (L16000300 Spectrum Two LiTa, Llantrisant, UK) spectrophotometer, and the potassium bromide $(\mathrm{KBr})$ pellet method was applied for spectral analysis.

\section{Results and discussion}

\section{Ultraviolet-visible spectroscopy}

Reduction of $\mathrm{Ag}$ (I) ions into silver nanoparticles during exposure to plant extract was visually evident as a result of the colour change (yellowish brown colour). The UVVIS spectra showed the appearance of single and SPR centered around $417 \mathrm{~nm}$. Figure 2 shows the effect of variation of $\mathrm{AgNO}_{3}$ concentrations onto the AgNPs formation. It is evident from Fig. 2 that only the intensity of band increases without affecting the band position, indicating the increment of number of AgNPs with

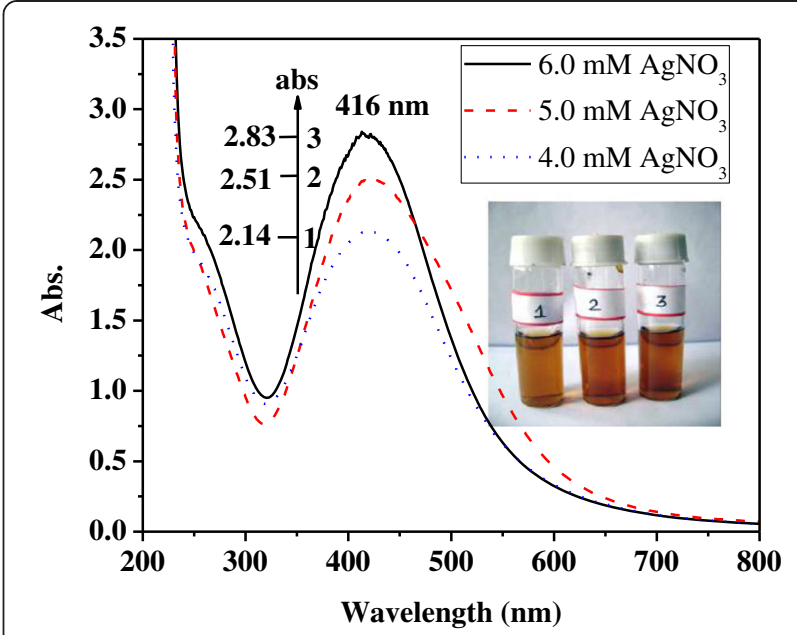

Fig. 2 UV-VIS absorption spectra of prepared AgNPs at different silver nitrate $\left(\mathrm{AgNO}_{3}\right)$ concentration

increasing $\mathrm{Ag}$ (I) $\left(\mathrm{AgNO}_{3}\right)$ concentration. Figure 3 shows the variation of the amount of leaf extract. Here also, the same trend is observed. AgNPs are formed through the reduction of silver ions by the plant leaf extract where the amino acids present in the extract are the reducing agents. So increasing the amount of plant leaf extract large numbers of active ingredients are available for the reduction of $\mathrm{Ag}(\mathrm{I})$ to $\mathrm{Ag}(0)$ causing an increase in intensity of the SPR band.

\section{Fourier transform infrared spectroscopy}

FTIR spectrum of the AgNPs is shown in Fig. 4. The peak at $1635 \mathrm{~cm}^{-1}$ is due to the $\mathrm{C}=\mathrm{O}$ stretching, and the other at $3441 \mathrm{~cm}^{-1}$ is due to the hydrogen bonded $-\mathrm{OH}$ and $\mathrm{NH}_{2}$ groups in the amino acids present in the leaf extract. From the FTIR spectrum, it can be concluded that the

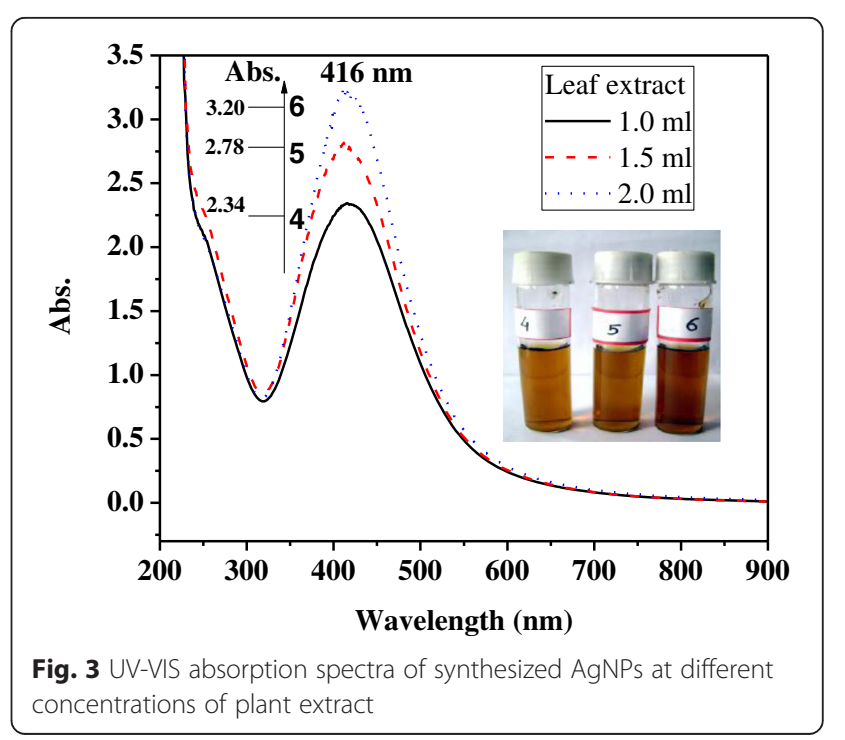




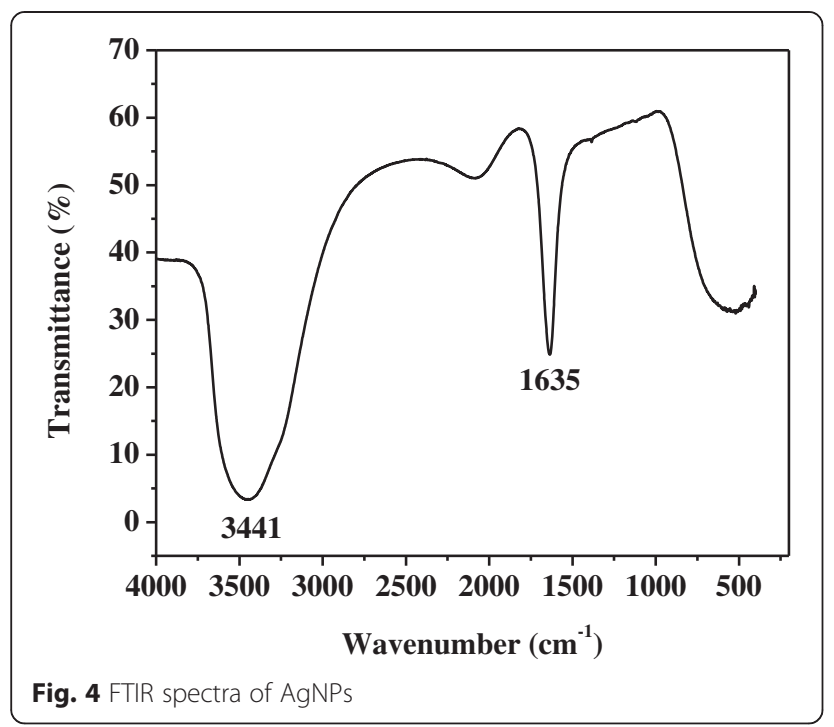

(a)

(c)
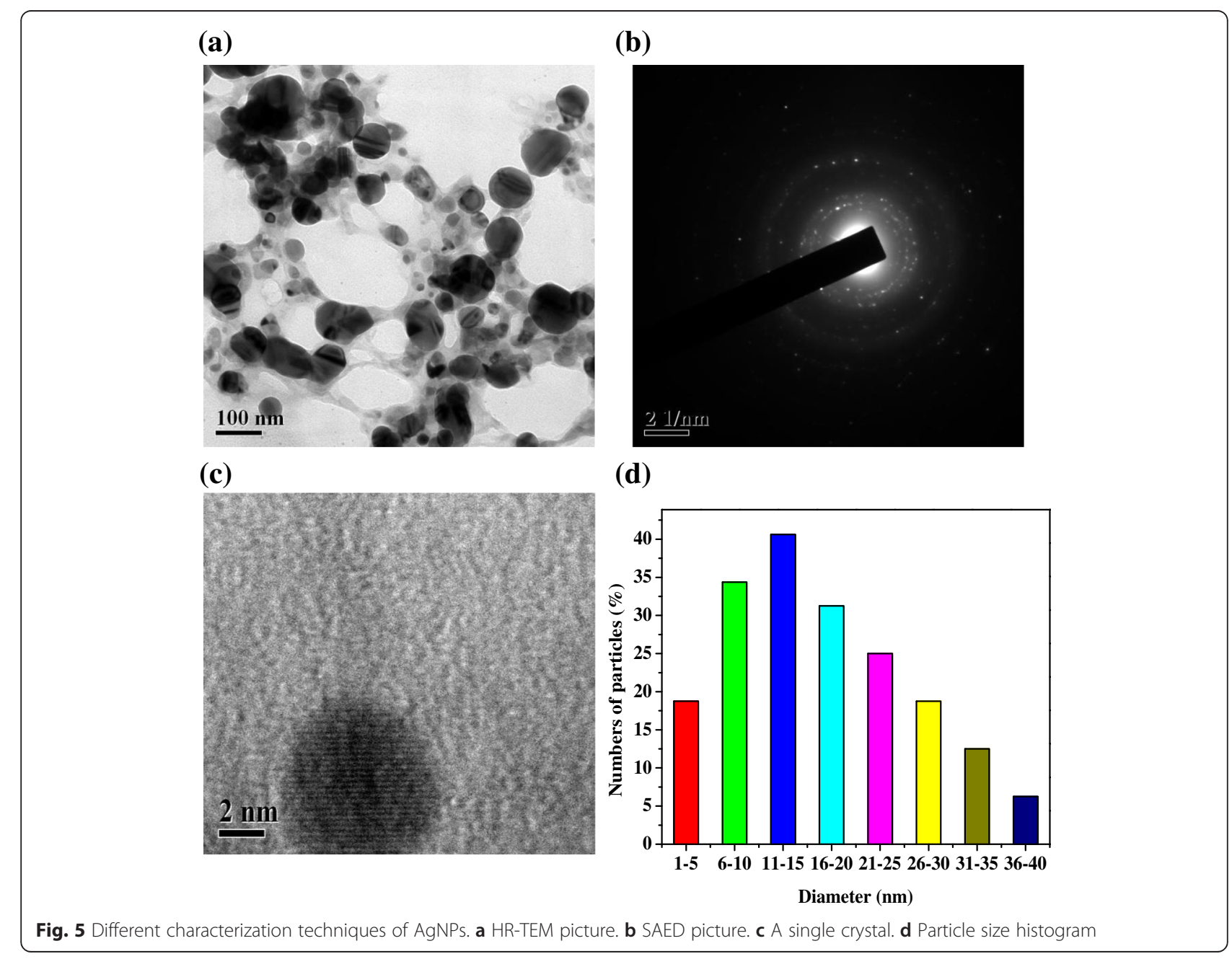

synthesized AgNPs are surrounded by amino acids. This suggests that the extract of Amaranthus gangeticus Linn have dual function, formation and stabilization of AgNPs in the aqueous medium.

\section{HR-TEM study}

The size and morphology of synthesized AgNPs are investigated by HR-TEM (Fig. 5). HR-TEM image indicates that the particles are predominantly globularshaped. Selected area electron diffraction (SAED) image reveals that the AgNPs are polycrystalline in nature (Fig. 5b, c). From Fig. 5d, it is evident that the average particle size distribution of the synthesized AgNPs ranges from 11-15 $\mathrm{nm}$.

\section{Antibacterial activity}

Antibacterial activity of nano silver hydrosol onto one Gram negative bacteria Shigella flexneri (ATCC-12022) and one Gram positive bacteria Bacillus subtilis (ATCC11774) is shown in Fig. 6a, b, respectively. In both cases, a clear inhibition zone appeared. It was also observed 

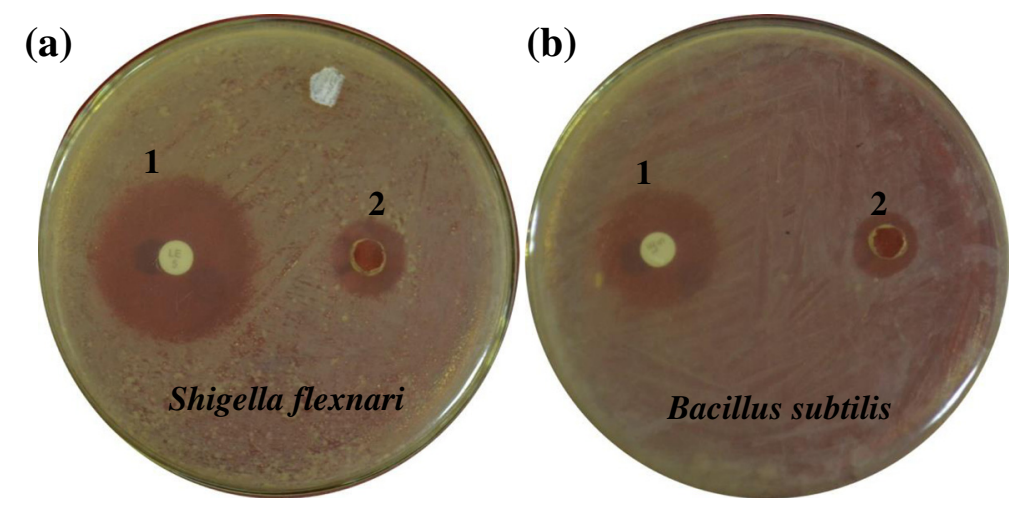

Fig. 6 Zones of inhibition against bacterial stain by the (1) levofloxacin and (2) synthesized AgNPs by agar-well diffusion method

that the zone of inhibition of Gram negative bacteria is slightly greater $(5.5 \mathrm{~mm})$ than that of the Gram positive bacteria $(4 \mathrm{~mm})$; a similar trend is also observed in case of levofloxacin, a broad spectrum antibiotic (marked 1 in Fig. 6).

\section{Antifungal activity}

Figure 7 shows the antifungal activity of prepared AgNPs. It was found that among the three tested different (AgNPs), $0.2 \mu \mathrm{g} / \mathrm{ml}$ concentration (marked 2 in Fig. 7) inhibits the growth of Sclerotinia sp. and produces a hollow zone around the applied AgNPs by interrupting the growth of plant pathogenic fungi Sclerotinia sp. At this concentration, silver nanoparticles directly damage the cell envelope by penetrating the cell and then binding to the DNA. The Ag-DNA complex prevents the DNA

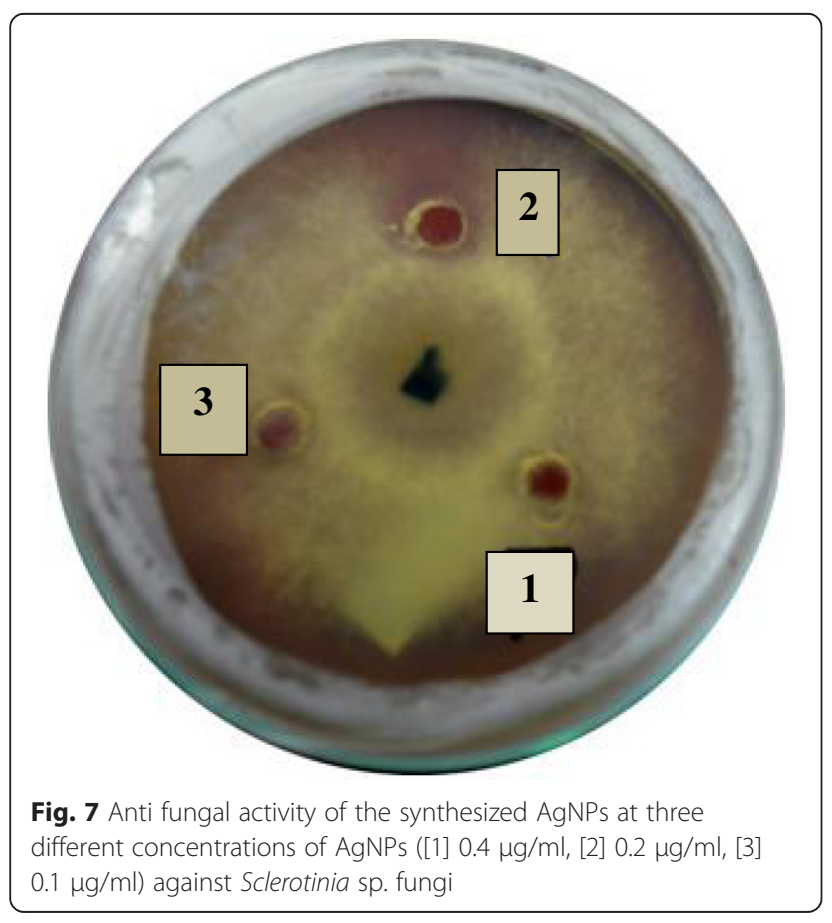

replication by rupturing the hydrogen bonds between adjacent purines and pyrimidines moieties.

\section{Degradation of Congo red dye}

The Congo red is a non-biodegradable and toxic azo dye. It originates generally from dyeing industries which pollute water. This leads to destroy the balance of aquatic environment. In the present investigation, $4.0 \mu \mathrm{g} / \mathrm{ml}$ of the synthesized AgNPs had been applied over the dye for its degradation. The result is shown in Fig. 8. From the UV plot (Fig. 8), it is observed that the absorption peak of the dye molecules gradually decreases as the time passes, and finally, the absorption peak vanishes and the colour of the solution changes from red to colourless. The Congo red degradation reaction was monitored by UV-VIS spectrophotometer (model: Shimudzu-1800). Congo red in water medium shows SPR band at $498 \mathrm{~nm}\left(\pi \rightarrow \pi^{*}\right)$ and at $338 \mathrm{~nm}$ $\left(n \rightarrow \pi^{*}\right)$ electron transition associated with azo group. In the presence of sodium borohydride, AgNPs help to

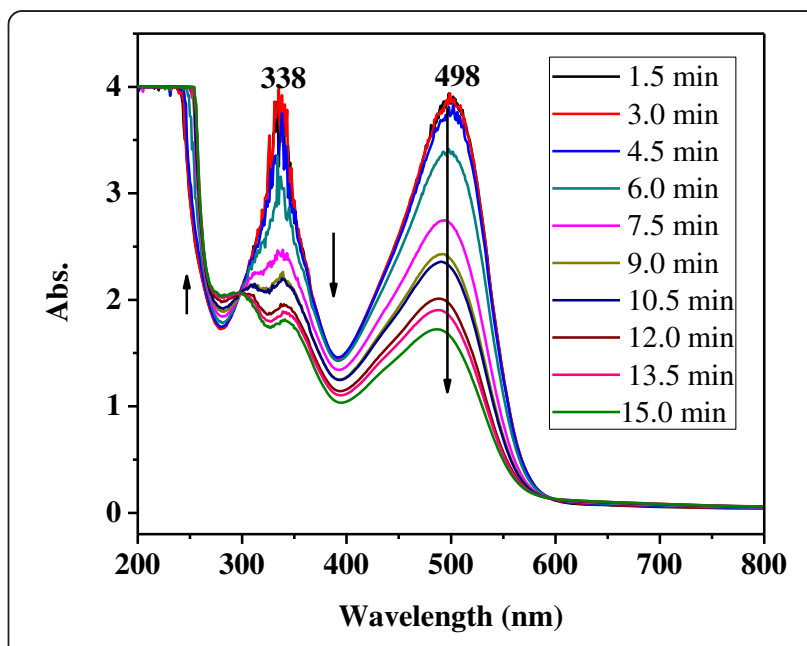

Fig. 8 Study of kinetics of the Congo red dye degradation by the synthesized AgNPs at a 1.5-min time interval 


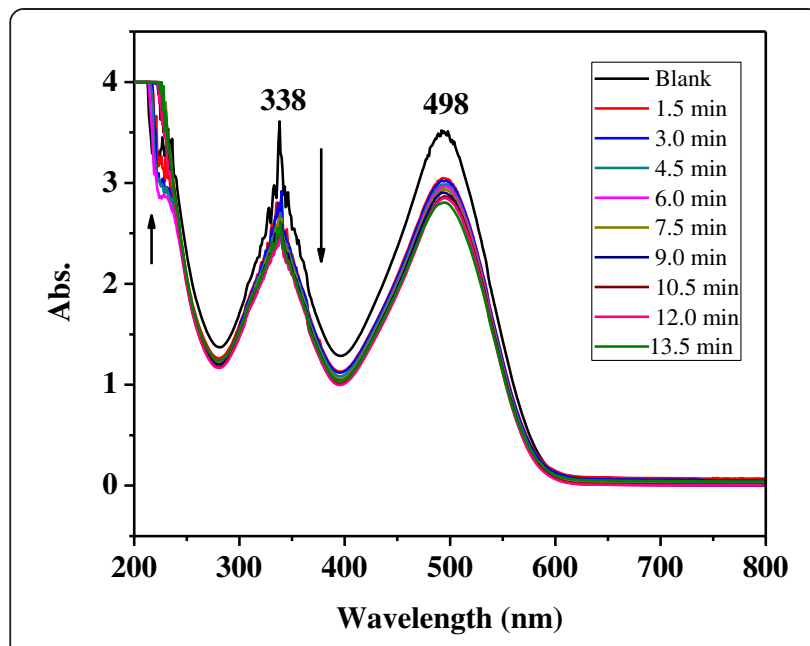

Fig. 9 Study of kinetics of the Congo red dye degradation by $\mathrm{NaBH}_{4}$ at a 1.5-min time interval

transfer the electron to azo bond in Congo red (acceptor) from $\mathrm{BH}_{4}^{-}$(donor) molecules. Only AgNPs have no considerable effect on degradation of Congo red solution. It is obvious that the presence of a strong reducing agent $\mathrm{NaBH}_{4}$ reduced the Congo red solution very slowly which is shown in Fig. 9. But, when the mixture of $\mathrm{NaBH}_{4}$ in anhydrous ethanol and AgNPs $(0.4 \mu \mathrm{g} / \mathrm{ml})$ is mixed with Congo red dye solution, the degradation of dye is completed within a few minutes. The result is shown in Fig. 8. So, the AgNPs prepared from the Amaranthus gangeticus Linn leaf extract can be used for the Congo red dye removal from the waste water.

\section{Conclusions}

An eco-friendly and convenient green method for the synthesis of silver nanoparticles from silver nitrate solution using Amaranthus gangeticus Linn leaf extract was developed. Formation of globular-shaped and well-dispersed AgNPs with an average particle size of 11-15 nm was confirmed by UV-VIS, FTIR, HR-TEM, and SAED. FTIR spectroscopic study confirmed that the amino acids present in the leaf extract reduces the $\mathrm{Ag}$ (I) to $\mathrm{Ag}(0)$ in the nanoscale. Silver nanoparticles prepared by the present method have promising applications as an activity against both Gram negative and Gram positive bacteria and fungi. The prepared AgNPs also showed efficient catalytic activity towards degradation of Congo red dye thus having potential for industrial application.

\section{Competing interests}

The authors declare that they have no competing interests.

\section{Authors' contributions}

HK, PPM, and TT synthesized the AgNPS, and TT characterized the AgNPS using TEM and UV-VIS spectroscopy. AP performed the antibacterial activity studies. PPM collected the Chinese spinach leaf and prepared the leaf extract. HK and TT performed the azo dye degradation properties using the prepared AgNPS. All authors read and approved the final manuscript.

\section{Acknowledgements}

The financial assistance of Midnapore College (Autonomous) is gratefully acknowledged.

\section{Author details}

${ }^{1}$ Postgraduate Division of Chemistry, Midnapore College (Autonomous), Midnapore, Paschim Medinipur 721101, West Bengal, India. ${ }^{2}$ Department of Botany, Midnapore College (Autonomous), Midnapore, Paschim Medinipur

721101, West Bengal, India. ${ }^{3}$ Department of Microbiology, Midnapore College (Autonomous), Midnapore, Paschim Medinipur 721101, West Bengal, India.

Received: 19 September 2015 Accepted: 5 November 2015

Published online: 12 November 2015

\section{References}

Ahmad N, Sharma S, Alam MK, Singh VN, Shamsi SF, Mehata BR, et al. Rapid synthesis of silver nanoparticles using dried medicinal plant of basil. Colloids Surf. 2010;81:81-6.

Awhad MA, Salem NM, Abdeem OA. Green Synthesis of silver nano particles using carob leaf extract and anti-bacterial activity. Int J Ind Chem. 2013;4:1-6.

Bar H, Bhui DK, Sahoo GP, Sarvar P, Pyne S, Misra A. Green synthesis of silver nano particles using seed extract of Jatrophacurcas. Colloid Surf A. 2009;348:212-6.

Bauer AW, Kirby WMM, Sherris JC, Turck M. Antibiotic susceptibility testing by a standardized single disk method. Am J Clin Pathol. 1966;45:493-6.

Bhattcharya R, Mukherjee P. Biological properties of naked metal nanoparticles. Adv Drug Deliv Rev. 2008;60:1289-306.

Dubey SP, Lahtinen M, Sillanpää M. Tansy fruit mediated greener synthesis of silver and gold nanoparticles. Process Biochem. 2010;45:1065-71.

El-Rafie MH, Mohamed AA, Shaheen TI, Hebeish A. Antimicrobial effect of silver nanoparticles produced by fungal process on cotton fabrics. Carbohydr Polym. 2010;80:779-82.

Ericka R-L, Iñiguez-Palomares R, Navarro RE, Herrera-Urbina R, Tánori J, IñiguezPalomares 3Claudia, et al. Synthesis of silver nanoparticles using reducing agents obtained from natural sources (Rumex hymenosepalus extracts). Nanoscale Res Lett. 2013;8:318.

Etheridge ML, Campbell SA, Erdman AG, Haynes CL, Wolf SM, McCullough J. The big picture on nanomedicine products. Nanomedicine NBM. 2013;9:1-14.

Jha AK, Prasad K. Green synthesis of silver nanoparticles using Cycas leaf. Inter J Green Nanotechnol Phys Chem. 2010;1(2010):110-7.

Jotterand F, Alexander AA. In: Hurst SJ, editor. Biomedical nanotechnology: managing the "Known Unknowns". Theranostic cancer nanomedicine and informed consent. Illinois: Springer; 2011. p. 413-30.

Kalidindi SB, Jadirdar BR. Nanocatalysis and prospects of green chemistry. Chem Sus Chem. 2012;5:65-75.

Lengke MF, Fleet ME, Southam G. Biosynthesis of silver nanoparticles by filamentous cyanobacteria from a silver (I) nitrate complex. Langmuir. 2007; 23:2694-9.

Mandal D, Bolander ME, Mukhopadhyay D, Sankar G, Mukherjee P. The use of microorganisms for the formation of metal nanoparticles and their application. Appl Microbiol Biotechnol. 2006;69:485-92.

Nalvothula R, Babu NV, Rama K, Ramchander M, Rudra MPP. Biogenic synthesis of silver nanoparticles using tectona grandis leaf extract and evaluation of their antibacterial potential. Int J ChemTech Res. 2014;6:293-8.

Prabhu S, Poulose EK. Silver nanoparticles: mechanism of antimicrobial action, synthesis, medical applications, and toxicity effects. Int Nano Lett. 2012;2:32-42.

Reyad-ul-Ferdous M, Shamim Shahjahan DM, Sharif T, Mohsina M. Present biological status of potential medicinal plant of amaranthus viridis: a comprehensive review. Am J Clin Exp Med. 2015;3:12-7.

Shankar SS, Ahmad A, Sastry M. Geranium leaf assisted biosynthesis of silver nanoparticles. Biotechnol Progr. 2003;19:1627-31.

Sharma VK, Yngard RA, Lin Y. Silver nanoparticles: green synthesis and their antimicrobial activities. Adv Colloid Interf Sci. 2009;145:83-96.

Shen Y, Friend CS, Jiang Y, Jakubczyk D, Swiatkiewicz J, Prasad PN. Nano photonics: interactions, materials and applications. J Phys Chem B. 2000;104: 7577-87.

Sivaram SK, Elango I, Kumar S, Santhanam V. A green protocol for room temperature synthesis of silver nano particles in seconds. Curr Scie. 2009;97: 1055-9. 
Srinivas Bagepalli, Kumar1Ashok, Lakshman Kuruba, KN Jayaveera. Comparative antipyretic activity of methanolic extracts of some species of Amaranthus Asian Pacific. J Trop Biomed. 2011; S47-S50.

Zayats M, Kharitonov AB, Pogorelova SP, Lioubashevski O, Katz E, Willner I.

Probing photoelectrochemical processes in Au-CdS nanoparticle arrays by surface plasmon resonance: application for the detection of acetylcholine esterase inhibitors. J Am Chem Soc. 2003;125:16006-14.

Zhang H, Wu M, Sen A. In: Cioffin R, editor. Nano-antimicrobials; silver nanoparticle antimicrobials and related materials. New York: Springer; 2012. p. 3-45.

Submit your manuscript to a SpringerOpen ${ }^{\circ}$ journal and benefit from:

- Convenient online submission

- Rigorous peer review

- Immediate publication on acceptance

- Open access: articles freely available online

- High visibility within the field

- Retaining the copyright to your article

Submit your next manuscript at $\gg$ springeropen.com 